\title{
(In)Visibilities that Vary: The Production of Aging Lesbian, Gay, Bisexual, Transgender, and Queer Subjects in Chronic Care
}

\section{Hannah $\mathrm{Kia}^{1}$}

Despite the recent emergence of empirical literature on expressions of systemic stigma and discrimination shaping the realities of older lesbian, gay, bisexual, transgender, and queer (LGBTQ) adults, particularly those interacting with systems of chronic care, these social conditions are yet to be theorized. Drawing on the theoretical traditions of Foucauldian governmentality and intersectionality, this paper constitutes a preliminary attempt at conceptualizing the production of aging LGBTQ subjects within the context of contemporary chronic care. Whereas governmentality is used to highlight issues of visibility that construct aging sexual and gender minorities as targets of subjugation in systems of chronic care, intersectionality is utilized to theorize variations in these processes of subject formation across subcategories of older LGBTQ adults. The paper concludes with implications of this theoretical analysis for further conceptualization and empirical inquiry, as well as broader systemic change, in the area of LGBTQ aging. [Article copies available for a fee from The Transformative Studies Institute. E-mail address: journal@transformativestudies.org Website: http://www.transformativestudies.org (C2019 by The Transformative Studies Institute. All rights reserved.]

KEYWORDS: LGBTQ, Lesbian, Gay, Bisexual, Transgender, Queer, Aging, Critical Gerontology, Foucault, Governmentality, Intersectionality, Chronic Care.

\footnotetext{
${ }^{1}$ Hannah Kia is a Ph.D. Candidate in Social and Behavioural Health Sciences at the University of Toronto. Her research interests largely centre on examining the social conditions and experiences of older lesbian, gay, bisexual, transgender, and queer (LGBTQ) adults. Her work is supported by a Canadian Institutes of Health Research (CIHR) Doctoral Research Award. She has published several theoretical papers addressing LGBTQ health in refereed journals.
} 